Editorial

\title{
La cirugía oncológicamente correcta del cáncer de ovario en la actualidad: dos sistemas, dos realidades
}

El cáncer de ovario es una enfermedad que carece de métodos eficaces de cribado, por lo que su diagnóstico es tardío en aproximadamente $70 \%$ de los casos. La razón fundamental de este problema estriba en el hecho de que el ovario es un órgano de localización pelvica sin conexión con el exterior. La pelvis junto con el abdomen forman una cavidad muy amplia denominada cavidad intra-abdominal. Entre la pelvis y el abdomen no existe clara separación, por lo que las enfermedades de una u otra van a afectar por contigüidad a los órganos existentes en ambas cavidades. Al formar una superficie tan amplia y distendible, los tumores que se desarrollan en su interior provocan una sintomatología tardía e inespecífica, lo que dificulta un diagnóstico precoz de estas enfermedades. Además, debemos tener en cuenta, que los carcinomas de ovario se diseminan con frecuencia a través de los ganglios linfáticos del espacio retroperitoneal a las regiones pelvicas y para-aórticas, con posible afectación de las estructuras vasculares, óseas y nerviosas de esas zonas. Para poder realizar una cirugía oncológicamente correcta, el cirujano debe de tener amplios conocimientos de la anatomía de las cavidades pelvica y abdominal, así como de todos los órganos y estructuras que las componen. A su vez el cirujano debe de estar familiarizado con las técnicas quirúrgicas relacionadas con diversas especialidades implicadas como son la cirugía ginecológica, digestiva, urológica y reconstructiva. Es, así mismo, importante que el especialista dedicado principalmente a la cirugía ginecológica oncológica domine técnicas de abordaje quirúrgicas tanto abiertas (laparotómicas) como cerradas (laparoscópicas). Es fundamental que a una paciente joven y con deseos de procreación, a la que casualmente se le diagnostica una tumoración ovárica maligna y encapsulada, se le pueda realizar una estadificación laparoscópica completa (incluyendo omentectomía y linfadenectomías pelvicas y para-aórticas) sin tener que someter a la paciente a una laparotomía. El resultado de la estadificación dictaminará la necesidad de realizar una castración quirúrgica definitiva con la extirpación del ovario contralateral y del útero; y la necesidad o no de dar quimioterapia adyuvante. Otro ejemplo donde se podría realizar una estadificación por vía laparoscópica con finalidades similares, sería en aquellas pacientes a las que ya se les ha realizado una histerectomía más doble anexectomía por enfermedad benigna y en la que la anatomía patológica definitiva se informa como un cáncer de ovario. Como ya adelanté al principio de este editorial, es muy frecuente encontrar a pacientes con un cáncer de ovario en estadio avanzado; con afectación de muchos órganos intra-abdominales y estructuras retroperitoneales. En estos casos es clave la realización de una buena citorreducción tumoral (la máxima que técnicamente se pueda practicar) para mejorar la respuesta al tratamiento antiblástico postoperatorio. Con frecuencia hay que extirpar segmentos intestinales y ocasionalmente el bazo u otras estructuras intra-abdominales. También es clave que el cirujano sepa solucionar las complicaciones intraoperatorias, en ocasiones serias, como son lesiones a órganos y estructuras colindantes: uréteres, vejiga, vasos sanguíneos importantes..., además de las postoperatorias que se puedan presentar, incluyendo: septicemias, hemorragias, trombosis, embolias, etc. Estas cirugías radicales tienen una finalidad curativa, pero dado el diagnóstico tardío de estos tumores, con frecuencia tienden a recidivar. A partir de este momento el objetivo se convierte en aumentar la supervivencia de estas mujeres, a corto y medio plazo, sin empeorar su calidad de vida. Ante una recidiva intra-abdominal objetivable, de más de un año de evolución desde su cirugía inicial, en una paciente con buenas condiciones médicas y sin metástasis extraperitoneales, es razonable plantearse una citorreducción secundaria antes del inicio de una segunda línea de quimioterapía. Estas cirugías son técnicamente más complicadas, por lo que el cirujano debe de estar preparado para afrontar un mayor número de complicaciones intra y postoperatorias y de mayor gravedad. En fases terminales estos tumores con 
frecuencia, provocan obstrucciones intestinales, difícilmente controlables mediante métodos conservadores, por lo que disminuye claramente la calidad de vida de estas mujeres. El ginecólogo oncólogo, responsable del cuidado asistencial de estas enfermas, también debe de tener los conocimientos adecuados para saber cuando está indicado una cirugía paliativa para solventar este tipo de situaciones. Además debe de tener muy claro cuales son los objetivos de la misma, intentando evitar procedimientos innecesarios. Los conocimientos que tienen que tener los facultativos para poder tratar adecuadamente a pacientes con cánceres de ovario, tienen que ser amplios y que abarquen diferentes especialidades quirúrgicas; además de poseer profundos conocimientos sobre la biología tumoral, agentes antiblásticos, tratamientos ionizantes y manejo del paciente terminal.

Es una realidad que cuatro años de especialidad MIR, formación actual de ginecólogos y obstetras en nuestro país, no son suficientes para manejar al paciente ginecológico oncológico de una manera integral y correcta, por lo que con frecuencia es necesaria la presencia de varios especialistas en el quirófano para realizar este tipo de intervenciones. Esto conlleva una peor utilización de recursos humanos además de crear mayor confusión para pacientes y familiares, durante el manejo postoperatorio y seguimiento de las mismas. La implantación de superespecialidades en países como EEUU, ha conseguido completar la formación del ginecólogo y convertirlo en un experto en el tratamiento de esta patología. Esta subespecialidad está gestionada y controlada por el Colegio de Ginecólogos y Obstetras, y ofrece una titulación oficial. Este organismo es así mismo el encargado de definir el número de ginecólogos oncológos necesarios para el país y de acreditar a los Hospitales Universitarios que quieren y pueden ofrecer este tipo de titulación. El centro donde se realice esta cirugía y la formación de especialistas, debe ser centro oncológico de referencia y contar con los recursos humanos y materiales para llevarlos a cabo, así como tener un numero suficiente de casos para ganar en experiencia y resultados, con la finalidad de crear una escuela que tenga viabilidad en el futuro.

Con el actual modelo sanitario español, llegar a un sistema parecido al americano es difícil. Los cambios necesarios para, de manera continua, mejorar las posibles deficiencias del sistema, son lentos y poco ágiles. Con la descentralización política y económica de la España actual, existe una tendencia a la atomización de la medicina nacional y local. La creación de muchos y medianos hospitales de gestión pública y/o privada, crea una mayor competencia entre instituciones, que tiene claras ventajas como la disminución de listas de espera y acarrea puntos débiles que debemos conocer y subsanar. La disgregación de patologías raras o complejas que se tratarían mejor en centros de referencias centralizados, donde existan verdaderos especialistas, es uno de ellos. España cuenta con uno de los mejores sistemas nacionales de salud a nivel mundial, y continuar mejorándolo debe ser nuestra obligación y nuestro reto. En particular si hablamos de enfermedades mortales, complejas y muy costosas como son los cánceres de ovario y por ende otras tumoraciones ginecológicas. Debemos realizar una planificación real de las necesidades actuales y futuras de nuestra sociedad en relación con estas patologías; determinando, entre otras, el número de especialistas y de Instituciones Sanitarias necesarias para tratar estas enfermedades, y convertir a éstas en centros de referencia por excelencia. Esto nos permitiría formar al ginecólogo oncólogo de manera integral, concentrar experiencia, mejorar nuestra capacidad asistencial, docente e investigacional. A medio plazo conseguiríamos además un mejor control del gasto sanitario; está suficientemente probado hoy en día, que el correcto tratamiento de estas patologías permite controlar y reducir su coste. En definitiva, conseguir el tratamiento más correcto, desde todos los puntos de vista, de esta enfermedad compleja y mortal que es el cáncer de ovario.

Ricardo Sáinz de la Cuesta Abbad Profesor Titular Universidad Autónoma de Madrid Departamento de Ginecología y Obstetricia Médico Adjunto. Fundación Jiménez Díaz-Capio Madrid (España) 